\title{
DESKRIPSI KESALAHAN MAHASISWA DALAM MENGGAMBAR TITIK KOORDINAT PADA DIMENSI DUA DAN DIMENSI TIGA
}

\author{
Firda Alfiana Patricia \\ Program Studi Pendidikan Matematika IKIP Budi Utomo Malang \\ firdaalfianapatricia1985@gmail.com
}

\begin{abstract}
Abstrak
Penelitian ini bertujuan untuk mendeskripsikan kesalahan yang ditemukan pada mahasiswa ketika menggambar titik koordinat pada dimensi dua dan dimensi tiga pada mata kuliah Geometri Analitik. Subjek penelitian merupakan 20 mahasiswa program studi Pendidikan Matematika IKIP Budi Utomo Malang Kelas 2019A yang terdiri dari 14 perempuan dan 6 laki-laki yang penentuannya menggunakan simple random sampling. Terdapat 15 mahasiswa yang melakukan kesalahan dan 5 mahasiswa yang sudah benar dalam menggambar titik koordinat pada dimensi dua, sedangkan dalam menggambar titik koordinat dimensi tiga ditemukan 12 mahasiswa yang melakukan kesalahan dan 8 mahasiswa yang sudah benar. Berdasarkan analisis data dengan menggunakan analisis wacana maka kesalahan yang ditemukan merupakan jenis kesalahan proses keterampilan (process skills errors) diantaranya tidak menggunakan kertas berpetak sehingga jarak antar titik tidak sama, titik koordinat tidak diberi nama, titik koordinat tidak dituliskan, bilangan pada sumbu koordinat tidak dituliskan dan keliru dalam menggambar sumbu koordinat yang benar.
\end{abstract}

Kata kunci: dimensi dua, dimensi tiga, titik koordinat, geometri analitik

\begin{abstract}
This study aims to describe the errors found in students when drawing coordinates in the two and three dimensions in the Analytical Geometry course. The research subjects were 20 students of the Mathematics Education study program at IKIP Budi Utomo Malang Class 2019A consisting of 14 women and six men whose determination was made using simple random sampling. Fifteen students who made mistakes and five students who were correct in drawing the coordinates in the second dimension, while in drawing the coordinates in the third dimension, 12 students made mistakes and eight students who were correct. Based on data analysis using discourse analysis, the errors found were process skills errors, including not using grid paper so that the distance between points is not the same, coordinate points are not named, coordinate points are not written, numbers on the coordinate axes are not written. and mistakenly drew the correct coordinate axes.
\end{abstract}

Keywords: two dimensions; three dimensions; coordinate point, analytical geometry 


\section{PENDAHULUAN}

Matematika adalah ilmu yang penting karena merupakan sebuah ilmu dasar. Matematika menjadi alat untuk mempelajari ilmu-ilmu yang lain. Matematika mempunyai posisi yang sangat berpengaruh, karena matematika dapat melatih mahasiswa untuk berpikir kritis (Listiana \& Sutriyono, 2018). Matematika merupakan mata pelajaran yang diberikan mulai dari sekolah dasar. Tujuannya adalah untuk membekali siswa agar berkemampuan berfikir logis, analitis, sistematis, kritis, dan kreatif, serta mampu bekerjasama. (Sholihah \& Mahmudi, 2015). Matematika berpotensi sangat besar untuk membekali siswa dalam menghadapi persaingan (Nahdi, 2019). Itulah alasan mengapa belajar ilmu Matematika sangatlah penting dan bermanfaat.

Ilmu Matematika harus dipelajarai secara bertahap. Dimulai dengan konsep yang paling dasar terlebih dahulu agar dapat lebih mudah memahami konsep yang lebih rumit. Hambatan atau kesulitan dalam mempelajari matematika di tingkat yang lebih tinggi akan dialami oleh mahasiswa jika materi dasar tidak terkuasai (Wulandari \& Gusteti, 2020). Perlu adanya analisis untuk mengetahui hambatan belajar mahasiswa agar dapat menjadi bahan pertimbangan dalam perbaikan pembelajaran selanjutnya. (Yusuf, R, \& W, 2017).

Ketika belajar ilmu Matematika, tentu tak sepenuhnya mudah dan selalu benar, pasti akan ditemukan hambatan-hambatan yang membuat mahasiswa salah dalam menjawab soal ketika dalam proses belajar tersebut. Mahasiswa melakukan kesalahan pada umumnya disebabkan karena tidak mengingat konsep yang sudah dipelajari, cenderung menghafal suatu konsep tanpa memahami makna dari konsep tersebut. Kadang juga tidak teliti dan terburu-buru dalam mengerjakan soal, cenderung menjawab soal dengan singkat, kesulitan membangun ide atau gagasan dan buntu ide dalam mengerjakan soal (Aryani \& Maulida, 2019). Jika dibandingkan dengan kesalahan lainnya, kesalahan memahami masalah lebih dominan. Selain itu ada juga kesalahan konsep dan prinsip, kesalahan prosedur \& algoritma, dan kesalahan penegasan jawaban (Wati \& Sujadi, 2017). Kesalahan-kesalahan tersebut berupa kesalahan fakta, konsep, prinsip, prosedur dan cara penyimpulan (Raharjo \& Christanti, 2020). Apabila hal tersebut tidak ditindaklanjuti oleh pengajar maka akan berdampak pada hasil belajar mahasiswa. Penguasaan mahasiswa terhadap materi tersebut menentukan tinggi atau rendahnya kemampuan matematikanya (Fitriatien, 2019). Menurut Newman (Fatahillah, N.T, \& Susanto, 2017) analisis kesalahan terdiri dari lima, yaitu kesalahan dalam membaca masalah (reading error), kesalahan dalam memahami masalah (comprehension error), kesalahan Prismatika: Jurnal Pendidikan dan Riset Matematika Vol. 4 No. 1 (2021) p-ISSN: 2654-6140, e-ISSN: 2656-4181 http://ejurnal.budiutomomalang.ac.id/index.php/prismatika 
dalam transformasi masalah (transformation error), kesalahan dalam keterampilan proses (process skill error), dan kesalahan dalam penulisan jawaban (encoding error).

Keberagaman tingkat intelegensi di dalam kelas juga menjadi salah satu faktor yang menyebabkan kesalahan yang dilakukan oleh mahasiswa menjadi berbeda-beda satu sama lain. Mahasiswa dengan kemampuan matematika yang tinggi dan mahasiswa yang berkemampuan sedang ditemukan mengalami kesulitan dalam menerapkan prinsip dan keterampilan, sedangkan mahasiswa yang memiliki kemampuan matematika lebih rendah mengalami kesulitan dalam memahami konsep, menerapkan prinsip, dan keterampilan (Dwidarti, Mampouw, \& Setyadi, 2019). Namun mahasiswa dengan kemampuan matematika tinggi, sedang dan rendah memiliki ranah kesalahan yang hampir sama karena pada intinya mereka kurang teliti dan terburu-buru dalam mengerjakan (Fitriyah, Pristiwati, Sa'adah, \& Nikmarocha, 2020).

Salah satu faktor yang juga membedakan kesalahan mahasiswa yang satu dengan yang lainnya adalah keterampilan dalam menentukan solusi untuk penyelesaian suatu pertanyaan. Keterampilan (skill) didefinisikan sebagai suatu kemampuan yang dimiliki dalam menggunakan suatu prosedur atau langkah-langkah ketika menyelesaikan suatu permasalahan. Adapun istilah yang juga sering digunakan yaitu algoritma, yang bisa diartikan sebagai langkah-langkah standar dalam menyelesaikan soal (Andar \& Ikman, 2016).

Kesalahan dalam menjawab soal diakibatkan oleh kesulitan yang tidak teratasi dengan baik. Berdasarkan hasil observasi awal, ditemukan kesalahan mahasiswa dalam menyelesaikan titik koordinat. Kesulitan-kesulitan tersebut tidak terlepas dari ketidakmampuan mahasiswa dalam merepresentasikan koordinat titik pada bidang koordinat kartesius (Subekti \& Rochmad, 2021). Kemampuan representasi matematis setiap orang pasti berbeda. Apabila terdapat sebuah permasalahan matematika yang sama kemudian diberikan kepada beberapa individu, maka akan mendapatkan hasil yang pasti berbeda (Deswantari, Setyadi, \& Mampouw, 2020).

\section{METODE PENELITIAN}

Tujuan dari penelitian ini adalah untuk mendeskripsikan kesalahan mahasiswa dalam menggambar titik koordinat pada dimensi dua dan dimensi tiga pada mata kuliah Geometri Analitik sehingga jenis penelitian ini merupakan deskriptif kualitatif. Penelitian ini dilaksanakan secara daring dikarenakan kondisi pandemi yang belum memungkinkan untuk Prismatika: Jurnal Pendidikan dan Riset Matematika Vol. 4 No. 1 (2021) 
dilaksanakan secara tatap muka. Pengambilan sampel penelitian yaitu 20 mahasiswa menggunakan Sample Random Sampling. Sample Random Sampling adalah jenis pengambilan sampel dimana setiap orang dalam populasi memiliki probabilitas yang sama untuk terpilih. Mahasiswa diminta untuk menggambar masing-masing sebuah titik koordinat pada bidang dimensi dua dan dimensi tiga dengan titik koordinat yang ditentukan sendiri oleh mahasiswa sehingga titik koordinat yang dihasilkan akan berbeda antar mahasiswa yang satu dengan yang lainnya. Indikator kesalahan yang digunakan untuk mengidentifikasi kesalahan mahasiswa ditunjukkan pada tabel 1 berikut ini.

\section{Tabel 1. Indikator Kesalahan Menurut Newman}

\begin{tabular}{|c|c|c|}
\hline No. & Tipe Kesalahan & Indikator \\
\hline 1. & $\begin{array}{l}\text { Reading Error (kesalahan } \\
\text { dalam membaca soal) }\end{array}$ & $\begin{array}{l}\text { Mahasiswa tidak dapat membaca kata-kata, } \\
\text { satuan,atau simbol-simbol dengan benar }\end{array}$ \\
\hline 2. & $\begin{array}{l}\text { Reading Comprehension } \\
\text { (kesalahan dalam memahami } \\
\text { soal) }\end{array}$ & $\begin{array}{l}\text { a. Mahasiswa tidak menuliskan apa yang } \\
\text { diketahui dalam permasalahan tersebut } \\
\text { b. Mahasiswa sudah menuliskan apa yang } \\
\text { diketahui dalam permasalahan namun masih } \\
\text { belum benar } \\
\text { c. Mahasiswa tidak menuliskan apa yang } \\
\text { ditanyakan dalam permasalahan tersebut } \\
\text { d. Mahasiswa sudah menuliskan apa yang } \\
\text { ditanyakan dalam permasalahan namun } \\
\text { masih belum benar }\end{array}$ \\
\hline 3. & $\begin{array}{l}\text { Transform Error (kesalahan } \\
\text { dalam transformasi soal) }\end{array}$ & $\begin{array}{l}\text { Mahasiswa belum benar dalam memilih operasi } \\
\text { yang digunakan untuk menyelesaikan } \\
\text { permasalahan }\end{array}$ \\
\hline 4. & $\begin{array}{l}\text { Process Skill (kesalahan } \\
\text { dalam keterampilan proses) }\end{array}$ & $\begin{array}{l}\text { a. Mahasiswa belum benar dalam } \\
\text { menggunakan kaidah atau aturan } \\
\text { matematika yang tepat dan sesuai } \\
\text { b. Mahasiswa tidak dapat memproses lebih } \\
\text { lanjut solusi dari penyelesaian } \\
\text { permasakahan tersebut } \\
\text { c. Mahasiswa melakukan kesalahan dalam } \\
\text { perhitungan }\end{array}$ \\
\hline 5. & $\begin{array}{l}\text { Encoding Error (kesalahan } \\
\text { dalam penulisan jawaban) }\end{array}$ & $\begin{array}{l}\text { a. Mahasiswa belum benar dalam menuliskan } \\
\text { satuan dari jawaban akhir } \\
\text { b. Mahasiswa tidak menuliskan kesimpulan } \\
\text { c. Mahasiswa menuliskan kesimpulan tetapi } \\
\text { belum benar }\end{array}$ \\
\hline
\end{tabular}




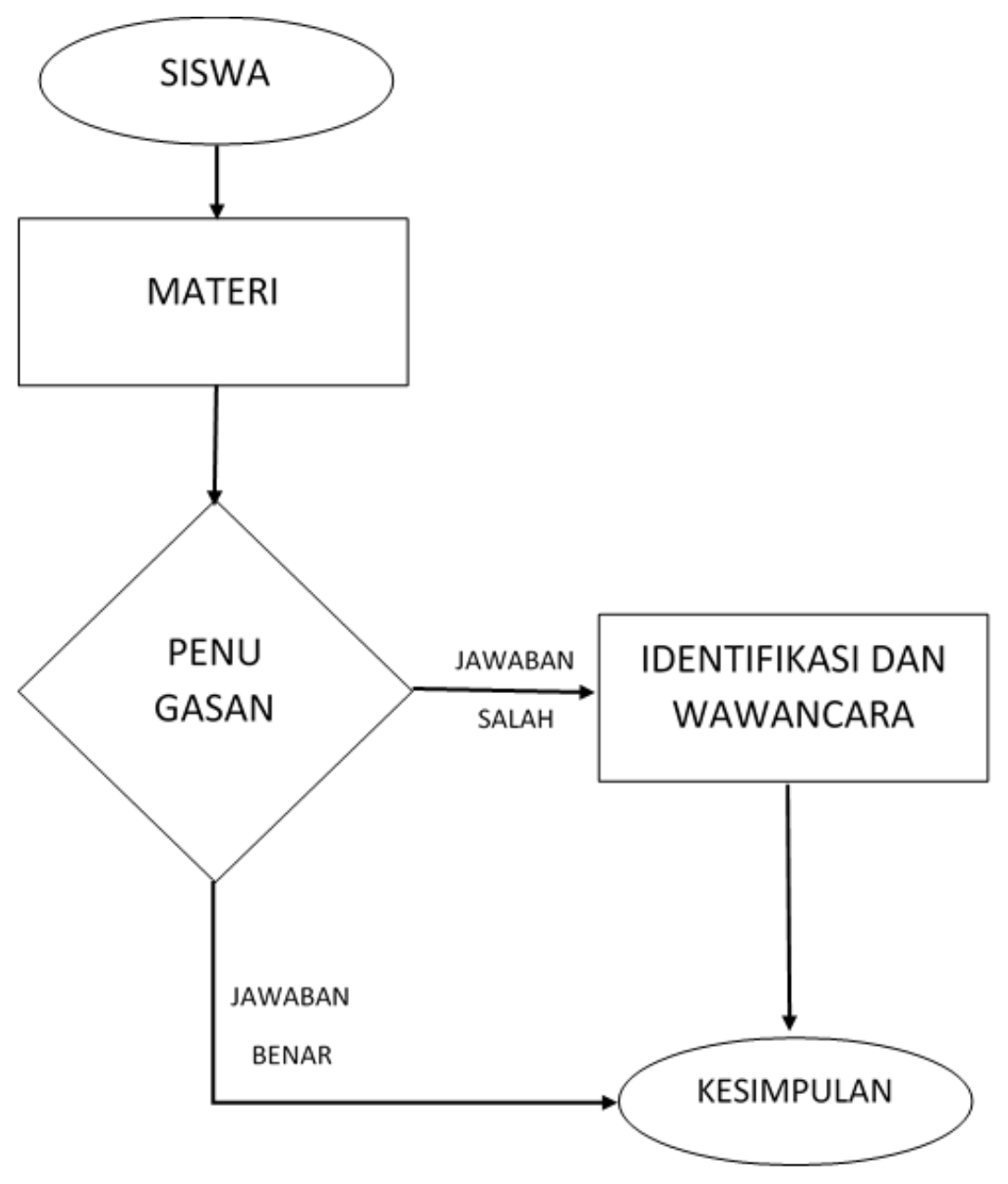

Diagram 1. Tahapan penelitian

Data yang dihasilkan dari penelitian ini adalah data tertulis dan data tidak tertulis. Data tertulis didapatkan dari hasil pekerjaan mahasiwa yang dikirimkan melalui aplikasi chatting, sedangkan untuk data yang tidak tertulis didapat dari tanya jawab melalui voice note pada aplikasi chatting juga.

\section{HASIL DAN PEMBAHASAN}

Kegiatan pengambilan data, peneliti menggunakan instrumen penelitian sebagai berikut "Gambarkan masing-masing sebuah titik koordinat pada dimensi dua dan dimensi tiga !". Instrumen penelitian tersebut berkaitan dengan mata kuliah Geometri Analitik. Jumlah total mahasiswa yang hadir dalam pengambilan data secara daring adalah 20 mahasiswa.

Hasil gambar titik koordinat pada dimensi dua yang dibuat oleh mahasiswa ditemukan sebanyak 15 mahasiswa yang masih salah dan 5 mahasiswa yang sudah benar, sedangkan pada gambar titik koordinat 
dimensi tiga ditemukan 12 mahasiswa yang masih salah dan 8 mahasiswa yang sudah benar. Kesalahan yang ditemukan pun beragam dan akan ditunjukkan dalam tabel berikut ini.

Tabel 2. Rincian Kesalahan Mahasiswa dalam Menggambar Titik Koordinat

\begin{tabular}{|c|c|c|}
\hline No. & Bidang Dimensi & Kesalahan \\
\hline \multirow[t]{5}{*}{1.} & Dua & $\begin{array}{l}\text { 1. Tidak menggambar pada kertas berpetak } \\
\text { sehingga jarak antar titiknya tidak sama }\end{array}$ \\
\hline & & 2. Titik koordinat tidak diberi nama \\
\hline & & $\begin{array}{l}\text { 3. Pada garis sumbu koordinat tidak } \\
\text { dituliskan bilangannya }\end{array}$ \\
\hline & & 4. Sumbu koordinat tidak diberi nama \\
\hline & & 5. Tidak dituliskan titik koordinatnya \\
\hline \multirow[t]{4}{*}{2.} & Tiga & 1. Keliru menentukan titik koordinat \\
\hline & & 2. Sumbu koordinat tidak diberi nama \\
\hline & & 3. Keliru menggambar sumbu koordinat \\
\hline & & $\begin{array}{l}\text { 4. Tidak menggambar pada kertas berpetak } \\
\text { sehingga jarak antar titiknya tidak sama }\end{array}$ \\
\hline
\end{tabular}

Berdasarkan rincian kesalahan mahasiswa tersebut apabila diidentifikasi sesuai dengan jenis kesalahan Newman maka tergolong ke dalam jenis kesalahan Process Skill Errors (kesalahan keterampilan proses) karena mahasiswa salah menggunakan kaidah atau aturan matematika yang benar. Kesalahan tersebut diantaranya tidak menggunakan kertas berpetak sehingga jarak antar titik tidak sama, titik koordinat tidak diberi nama, titik koordinat tidak dituliskan, bilangan pada sumbu koordinat tidak dituliskan dan keliru dalam menggambar sumbu koordinat yang benar.

Salah satu contoh mahasiswa yang melakukan kesalahan dalam menggambar titik koordinat pada dimensi dua adalah mahasiswa dengan inisial LA yang ditunjukkan pada gambar 1. Mahasiswa LA tidak menggambar pada kertas berpetak sehingga jarak antar titik tidak sama. Kemudian yang dicantumkan hanya nama titik koordinatnya saja namun titik koordinatnya tidak dituliskan sehingga membingungkan bagi yang membaca. Ketika dikonfirmasi melalui voice note, berikut petikan wawancara dengan mahasiswa LA. berpetak?"

Peneliti (P) : "Mengapa Anda tidak menggambar di kertas

$$
\begin{array}{ll}
\text { LA } & \text { : "Saya kira boleh di kertas biasa, Bu." } \\
\text { P } & \text { : "Jarak antar titik kan jadinya tidak sama jaraknya," } \\
\text { LA } & \text { : "Hehehe...Iya, Bu." }
\end{array}
$$


P : "Lalu mengapa tidak dituliskan titik koordinatnya?, Kan jadi bingung membacanya karena harus mencocokkan dulu dengan sumbunya,"

LA : "Iya, Bu. Saya lupa,"

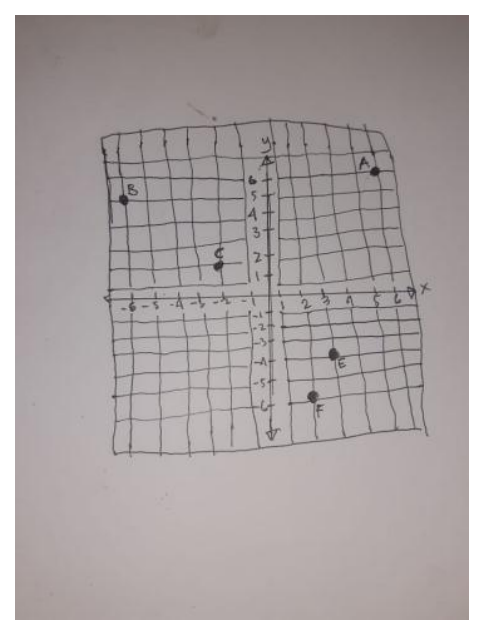

\section{Gambar 1. Contoh jawaban mahasiswa yang bernilai salah pada} nomor 1

Mahasiswa dengan inisial AD ini menggambar titik koordinat pada dimensi dua dengan benar seperti ditunjukkan pada gambar 2. Mahasiswa AD sudah menggambar titik koordinat pada kertas berpetak sehingga antar titik jaraknya sama. Kemudian nama titik koordinat beserta titiknya sudah dituliskan sehingga mudah untuk dibaca. Sumbu koordinat juga sudah dituliskan namanya beserta dengan bilangannya.

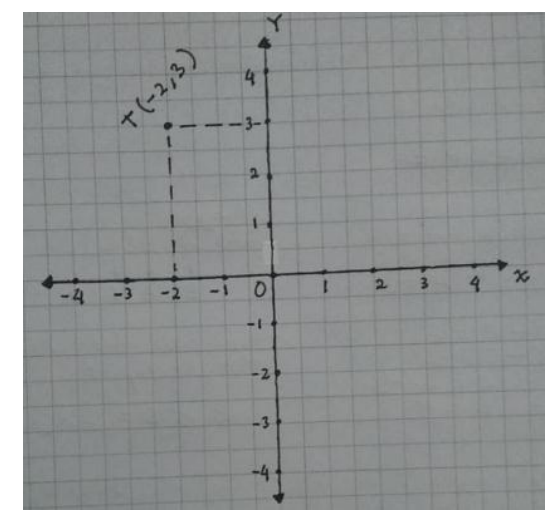

\section{Gambar 2. Contoh jawaban mahasiswa yang bernilai benar pada nomor 1}

Selanjutnya salah satu contoh mahasiswa yang melakukan kesalahan dalam menggambar titik koordinat pada dimensi tiga adalah mahasiswa dengan inisial MA yang ditunjukkan pada gambar 3. Mahasiswa MA sudah Prismatika: Jurnal Pendidikan dan Riset Matematika Vol. 4 No. 1 (2021) p-ISSN: 2654-6140, e-ISSN: 2656-4181 
mengerjakan dalam kertas berpetak namun keliru dalam menentukan posisi garis sumbu koordinat sehingga jarak antar titik-titiknya tidak sama karena tidak sesuai dengan petaknya. Berikut hasil petikan wawancara melalui voice note dengan mahasiswa MA.

P : "Mengapa Anda bisa keliru dalam menggambar sumbu koordinat pada dimensi 3?"

MA : "Iya, Bu. Saya bingung karena belum paham,"

P : :Kenapa waktu diterangkan tidak bertanya kalau belum paham?"

MA : "Iya, Bu. Saya malu. Jadi saya menebak-nebak saja kira-kira nggambarnya begitu,"

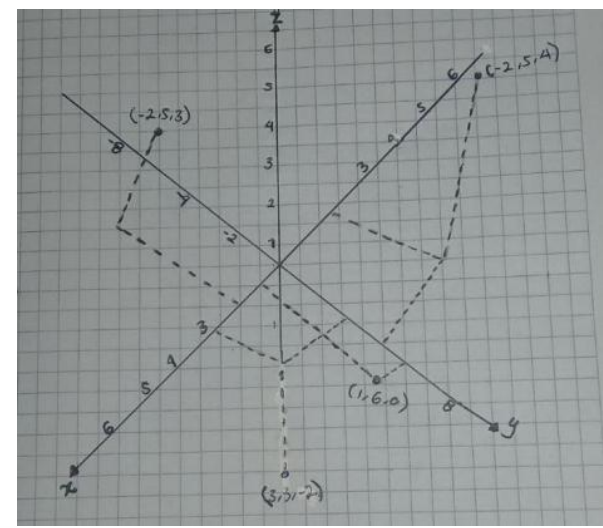

Gambar 3. Contoh jawaban mahasiswa yang bernilai salah pada nomor 2

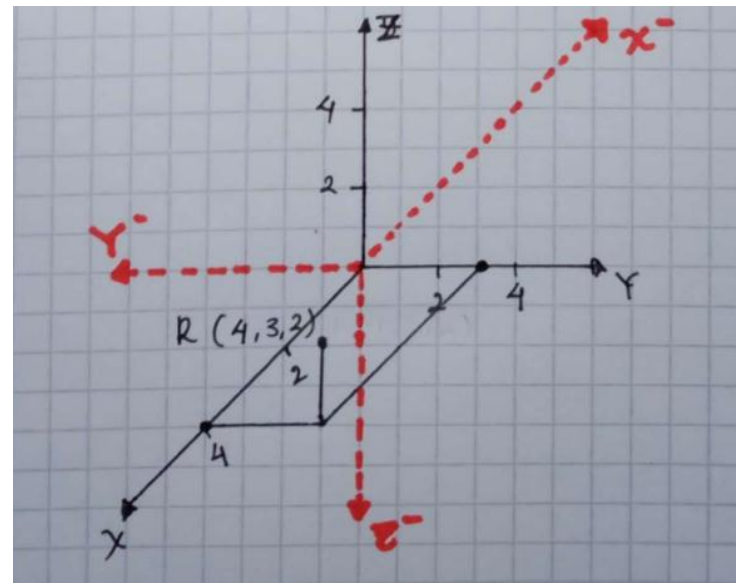

\section{Gambar 4. Contoh jawaban mahasiswa yang bernilai benar pada nomor 2}

Setelah memperhatikan kesalahan-kesalahan yang dilakukan oleh mahasiswa tersebut, peneliti menjelaskan lagi melalui rekaman video tentang langkah-langkah dalam menggambar titik koordinat pada bidang

Prismatika: Jurnal Pendidikan dan Riset Matematika Vol. 4 No. 1 (2021) p-ISSN: 2654-6140, e-ISSN: 2656-4181

http://ejurnal.budiutomomalang.ac.id/index.php/prismatika 
Cartesius baik dalam dua dimensi maupun tiga. Tujuannya supaya mahasiswa yang kesulitan dalam membayangkan letak titik koordinat pada dimensi dua dan dimensi tiga dapat lebih memahami. Untuk penelitian lanjutan diharapkan akan muncul media pembelajaran tiga dimensi yang bisa digunakan oleha mahasiswa untuk praktek menentukan titik koordinat pada bidang dimensi dua maupun dimensi tiga.

\section{KESIMPULAN DAN SARAN}

Hasil penelitian menunjukkan bahwa masih ada kesalahan yang ditemukan pada mahasiswa kelas 2019-A Program Studi Pendidikan Matematika IKIP Budi Utomo Malang dalam menggambar titik koordinat bidang dimensi dua dan dimensi tiga. Kesalahan yang ditemukan beragam diantaranya tidak menggunakan kertas berpetak sehingga jarak antar titik tidak sama, titik koordinat tidak diberi nama, titik koordinat tidak dituliskan, bilangan pada sumbu koordinat tidak dituliskan dan keliru dalam menggambar sumbu koordinat. Diharapkan mahasiswa lebih banyak berlatih lagi agar semakin memahami langkah-langkah dalam menggambar titik koordinat. Dosen juga diharapkan lebih sabar dan telaten dalam membimbing mahasiswanya agar tujuan pembelajaran dapat tercapai.

\section{DAFTAR RUJUKAN}

Andar, \& Ikman. (2016). Deskripsi Kesalahan Siswa dalam Menyelesaikan Soal-Soal Ujian Semester Matematika Kelas VIII SMP Negeri 10 Kendari. Jurnal Penelitian Pendidikan Matematika, Vol. 4, No. 2.

Aryani, I., \& Maulida. (2019). Analisis Kesalahan Siswa dalam Menyelesaikan Soal Matematika melalui Higher Order Thinking Skill (HOTS). Jurnal Serambi Ilmu, Volume 20, Nomor 2.

Deswantari, E., Setyadi, D., \& Mampouw, H. L. (2020). Representasi Matematis Siswa dalam Memecahkan Masalah Matematika Materi Poligon. Jurnal Pendidikan Matematika Raflesia, Vol. 05, No. 01.

Dwidarti, U., Mampouw, H. L., \& Setyadi, D. (2019). Analisis Kesulitan Siswa dalam Menyelesaikan Soal Cerita pada Materi Himpunan. Journal Cendekia: Jurnal Pendidikan Matematika, Vol. 03, No. 02.

Fatahillah, A., N.T, Y. F., \& Susanto. (2017). Analisis Kesalahan Siswa dalam Menyelesaikan Soal Cerita Matematika Berdasarkan Tahapan Newman Beserta Bentuk Scaffolding yang Diberikan. Kadikma, 40-51.

Fitriatien, S. R. (2019). Analisis Kesalahan dalam Menyelesaikan Soal Cerita Matematika Berdasarkan Newman. Jurnal Ilmiah Pendidikan Matematika, Vol. 4, No. 1. 
Fitriyah, I. M., Pristiwati, L. E., Sa'adah, R. Q., \& Nikmarocha, Y. W. (2020). Analisis Kesalahan Siswa dalam Menyelesaikan Soal Cerita Koordinat Cartesius menurut Teori Kastolan. Al-Khwarizmi: Jurnal Pendidikan Matematika dan Ilmu Pengetahuan Alam, Vol. 8, No. 2, 109-122.

Listiana, A. D., \& Sutriyono. (2018). Analisis Kesalahan Siswa dalam Menyelesaikan Soal Cerita pada Materi Himpunan bagi Siswa Kelas VII SMP Semester I Tahun Ajaran 2016/2017. Jurnal Pendidikan Berkarakter Vol. 1 No. 1, 60-65.

Nahdi, D. S. (2019). Keterampilan Matematika Di Abad 21. Jurnal Cakrawala Pendas Vol. 5 No. 2, 133-140.

Raharjo, A. M., \& Christanti, A. D. (2020). Analisis Kesalahan Siswa Kelas VIII SMP Kanisius Gayam dalam Menyelesaikan Soal Relasi dan Fungsi. Seminar Nasional Pendidikan Matematika.

Sholihah, D. A., \& Mahmudi, A. (2015). Keefektifan Experiential Learning Pembelajaran Matematika MTs Materi Bangun Ruang Sisi Datar. Jurnal Riset Pendidikan Matematika Vol. 2 No. 2, 175-185.

Subekti, F. E., \& Rochmad, I. (2021). Kemampuan Representasi Visual Siswa dalam Memecahkan Masalah Sistem Koordinat Kartesius. PRISMA Prosiding Seminar Nasional Matematika, (pp. 217-222).

Wati, M. K., \& Sujadi, A. A. (2017). Analisis Kesalahan dalam Menyelesaikan Masalah Matematika dengan Menggunakan Langkah Polya Siswa Kelas VII SMP. Jurnal Prisma Universitas Suryakancana, Vol. VI, No. 1.

Wulandari, S., \& Gusteti, M. U. (2020). Analisis Kesalahan Menyelesaikan Soal Trigonometri Siswa Kelas X SMA. Math Educa Journal 4(1), 64-80.

Yusuf, Y., R, N. T., \& W, T. Y. (2017). Analisis Hambatan Belajar (Learning Obstacle) Siswa SMP Pada Materi Statistika. Aksioma Vol. 8 No. 1, 7686. 